[ CONNECTING EMPLOYERS, EDUCATIONAL INSTITUTIONS, AND WORKERS

\title{
Addressing the Needs of Health Care Employers:
}

\section{Tri-County Health Care Industry Partnership}
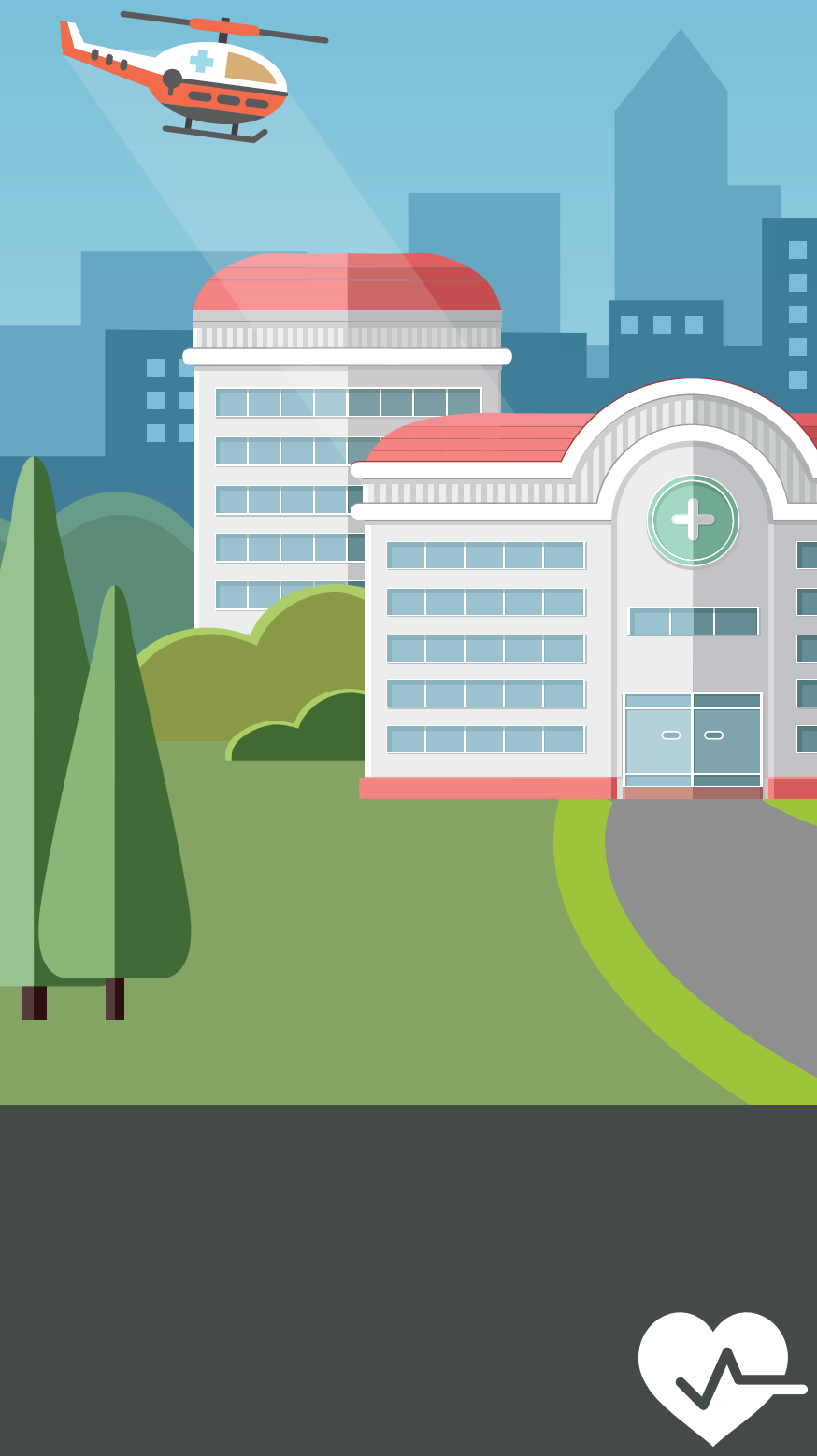


\section{Overview}

A critical nursing shortage in western Pennsylvania in 2002 drove the creation of the Tri-County Health Care Industry Partnership, which comprises three employer-led consortia in counties to the north and east of Pittsburgh. ${ }^{1}$ Early that year, health care providers in Indiana County grew increasingly concerned about the shortage of health care workers - in particular, nurses—-to fill their employment needs. There simply weren't enough trained health care workers to fill all the positions, which led employers, educational institutions, and human service and workforce development agencies from across Indiana County to gather to discuss the shortage of workers and ways to address it. A follow-up meeting with the Tri-County Workforce Investment Board (WIB) led to a partnership that then applied for a Critical Job Training grant from the Pennsylvania Department of Labor and Industry. In September 2002, the Tri-County WIB was awarded $\$ 225,000$ on behalf of the Indiana County Health Care Careers Consortium; that funding was used to train 278 registered nurses, licensed practical nurses, and certified nursing assistants in not just Indiana County, but in Butler and Armstrong counties as well. The grant also paid for seminars to provide continuing education units (CEUs) for both direct-care workers and nursing professionals. 


\section{While the need for skilled health care workers that initially brought employers together is still crucial today, equally important is the peer-to-peer learning and problem-solving that takes place when members of the partnership can engage with each other in tackling similar issues in the ever-changing health care industry.}

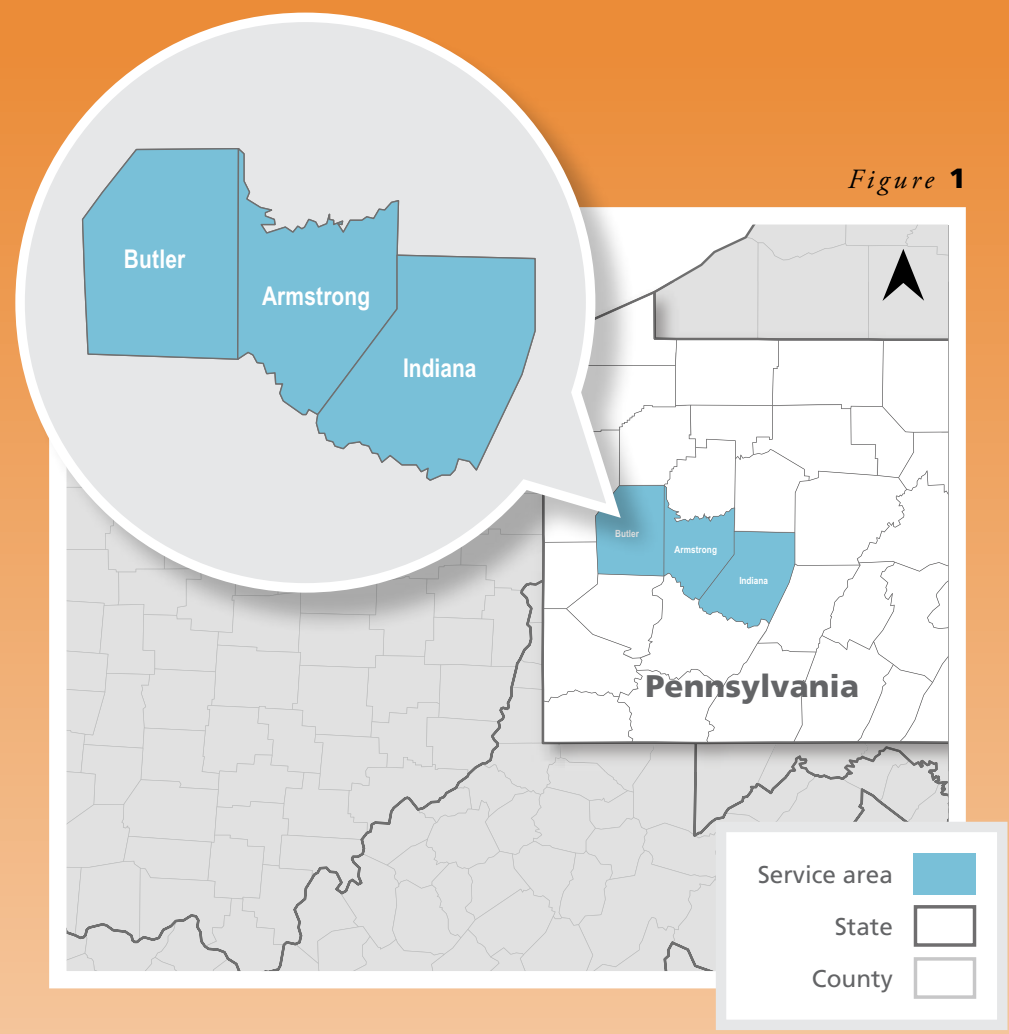

This Critical Job Training grant-which despite being initiated in Indiana County provided resources to health care workers in all three counties-was the impetus for forming the Tri-County Health Care Industry Partnership. In this partnership, the three consortia from Armstrong, Butler, and Indiana Counties work collaboratively to meet the employment and training needs of the health care industry across the region (see Figure 1). How? Three ways, primarily: They identify and address common training needs across the region, they engage with school systems to inform students about jobs in the health care industry, and they focus on efforts to recruit and retain health care workers. And while the need for skilled health care workers that initially brought employers together is still crucial today, equally important according to the six individuals we interviewed is the peer-to-peer learning and problem-solving that takes place when members of the partnership can engage with each other in tackling similar issues in the ever-changing health care industry. 


\section{Employment by industry in the Tri-County Region}

\section{Health care and social assistance}

Retail trade

Manufacturing

Accommodation and food services

Wholesale trade

Construction

2

Percent

Source: Bureau of Labor Statistics, QCEW (2014).

The Tri-County region is home to nearly 350,000 residents, with Butler County the largest at approximately 186,000 , followed by Indiana County at 88,000 and Armstrong County at $68,000 .^{2}$ As illustrated in the graph above, nearly 17 percent of the region's employment is found in the health care and social assistance industries, followed by retail trade and manufacturing (see Figure 2 ).

\section{Partnership Structure}

The Tri-County Health Care Industry Partnership brings together health care employers, educational institutions, and workforce development agencies to address the employment needs of the health care providers in the region. A steering committee comprised of chairs and co-chairs of each county consortium meets quarterly and coordinates the activities of the three counties (see Figure 3 ).

Employers, who make up about 70 percent of the Tri-County Partnership, take the lead in identifying the training needs of the health care sector within the three-county area. While each county consortium may have a different mix of members, all include employers, educational institutions, the Tri-County WIB, and the county's PA CareerLink. The Tri-County WIB is a critical player in the partnership structure, serving as both the fiscal agent and coordinating body of the three consortia. The WIB also conducts an annual assessment of the employers in the partnership to identify training needs for the coming year.

By design, the funds for training provided through Pennsylvania's Industry Partnership Worker Training Grant can be used for incumbent workers only, with few exceptions. This stems from the fact that although incumbent workers comprise the majority of the labor force, most of the workforce dollars were geared toward those without jobs. In 2005, Pennsylvania changed its workforce development strategy: That year, the Pennsylvania General Assembly allocated funds to establish employer-led partnerships in key industries throughout the State that would focus mainly on enhancing the skills and advancement opportunities of incumbent workers. Health care is one of these key industries.

Since 2005, the Tri-County WIB has applied annually for Industry Partnership Capacity Building and Training Funds on behalf of the partnership; to date the WIB has received about $\$ 1.8$ million and has trained more than 4,100 people. In addition to this funding, health care employers in the Tri-County region have contributed nearly $\$ 1.9$ million in both cash and in-kind funds. Employers are required to match dollar for dollar the funds provided to the Industry Partnership.

Driven by a desire to provide better care and create more competitive organizations that are attractive to prospective employees, consortium employers provide training opportunities aimed at increasing and enhancing employees' knowledge and skills, with the goal of improved patient care. All of the workers trained through the industry partnership receive a credential, a certificate, or CEUs.

Although the partnership's training needs vary by year, much of the training dollars are used for certified nursing aides (CNAs) because of high demand. 
The Industry Partnership grant also allows employers to provide "innovative" training for purposes beyond what is required by state and federal regulations, including employee engagement, leadership and management for nurses, and best practices for employee retention. Employers believe this kind of training leads to improved patient care as well as improved employee retention and satisfaction. If not for the partnership funding, say several of the partnership's employers, it is unlikely this type of training would take place.

Educational institutions play an important role in the partnership as well. The community colleges and vocational and technical schools in the counties served by the consortia provide training for health care workers, develop curricula to meet employer needs, and engage with school systems to promote health care careers. In addition, several of the partnership members serve on advisory committees of the vocational and technical schools that offer health care-related programs, thus providing direct input about the specific skills and training needed to address industry demands. Advisory committee meetings also provide an opportunity for employers to relay to the educational institutions the value and importance of "soft skills," such as dressing appropriately and showing up on time for interviews. Working through the Butler County Area Vocational-Technical School, members of the Butler consortium have done mock interviews with students to address issues raised by employers. In addition, members of the consortium will assess a student's clinical skills to help him or her be better prepared in advance of meeting with prospective employers when ready for employment.
Similarly, consortium members visit local middle and high schools to inform students and guidance counselors about the many career opportunities available in the health care fields. They advise students of the courses that will facilitate success in the health care sector-including biology, chemistry, and algebra — and how these courses are essential not just for entering the field, but for progressing in it as well. They also encourage students to participate in career fairs.

Additional partnership members include county representatives from the PA CareerLink system, who provide services to both employers and jobseekers. Employees from the CareerLink offices in Armstrong, Butler, and Indiana Counties inform members of regional labor market trends, as well as provide information regarding who is looking for work in the health care field and with what skill sets. Through job clubs, the CareerLink offices provide information to jobseekers about job searching techniques, interviewing skills, and workplace etiquette skills, which employers we interviewed indicate are crucial for employment. Job clubs provide a supportive environment in which jobseekers can engage with others looking for work. Given that Industry Partnership funds can be used for incumbent training only, employers can use on-the-job-training dollars to get new hires up to speed, a valuable benefit to the employers. Another tool for employers provided through CareerLink is its Job Gateway online portal that allows employers to post their job openings and jobseekers to post their resumes. Employers can search this portal to locate jobseekers in the area with specific skills; for their part, jobseekers can scan job postings for employment opportunities.

Figure $\mathbf{3}$

Organizational structure of the Tri-County Health Care Industry Partnership

Tri-County Workforce Investment Board (Fiscal Agent)

Tri-County Health Care Industry Partnership Steering Committee (Comprised of Chairs of the County IPS)

Butler County Health Care Consortium

Employers, Tri-County WIB, PA Career Link-Butler, Butler Area Votech School, Butler Community College, Butler Chamber of Commerce
Armstrong County Health Care Consortium

Employers, Tri-County WIB,

PA Career Link-Armstrong,

Lenape Practical Nursing Program,

Lenape Technical School,

Armstrong Educational Trust
Indiana County Health Care Careers Consortium
Employers, Tri-County WIB,

PA Career Link-Indiana, Indiana

County Technology Center,

Westermoreland County

Community College, Indiana

University of PA, Indiana

Chamber of Commerce 


\section{Educational institutions play an important role in the partnership as well. The community colleges and vocational and technical schools in the counties served by the consortia provide training for health care workers, develop curriculum to meet employer needs, and engage with school systems to promote health care careers.}

\section{Successes and obstacles}

The regional focus of this partnership facilitates interaction among the employers, educational institutions, and workforce development organizations to address the specific needs of the local economy. The partnership structure also allows for economies of scale, according to those we interviewed. For example, engaging with multiple employers allows for more efficient use of training funds and employee time: The more workers that are trained, the lower the per-worker training cost and the greater the likelihood that training can remain local. Staffing, retention, time commitment, and funding are ongoing challenges the consortium members face; however, those we spoke with cited the collaboration, learning, and problem-solving that take place among members as successes.

\section{STAFFING NEEDS AND RETENTION}

Without exception, everyone we interviewed mentioned that filling entry-level positions remains a challenge, specifically for certified nursing assistants (CNAs). Long-term-care facilities, in particular, rely on CNAs to fulfill the needs of their aging patients. Consortium members pointed to several factors contributing to the CNA shortage: significant turnover in the occupation, the physical demands of the job, and the relatively low pay. With state training dollars available only for incumbent workers, some are training for and transitioning to CNA roles from other positions and experiencing wage gains. But with such high demand for CNAs throughout the Tri-County region, training incumbent workers is not sufficient to fill the need. So employers in the partnership provide scholarships both to train those interested in becoming CNAs as well as to fill the demand for other health care workers, including RNs and LPNs.

Scholarships are one way the consortia provide additional training to meet staffing needs for in-demand occupations. Each county within the Tri-County Industry Partnership raises money for scholarships through annual employee recognition events. These events are considered a success for the Tri-County Partnership in a number of ways.
First, the events raise funds for scholarships to train those interested in entering the health care field or moving up the career ladder. Second, publicly recognizing employees for their dedication and commitment to serving the health care needs of the community contributes to employee retention. Third, the events are an opportunity to let the community know about the industry partnership and to engage with other employers interested in being part of the consortium.

The consortium members also leverage each other's expertise to meet training and staffing needs. For example, the co-chair of the Indiana County Health Care Careers Consortium, Diana Rupert, who directs the LPN program at Indiana County Technology Center (ICTC), reported that consortium members' clinical facilities provide sites for student clinicals, offer job shadowing opportunities for her students, and pair students with nurse managers when doing rotations. Both LPNs and RNs receive nurse's aide training during their schooling, which allows them to be employed as CNAs. Students can assist clinical facilities when staffing is an issue and their school schedules permit. 
While members of the Tri-County Partnership work together to provide training across the region, each of the three consortia also works within its respective county to address specific health care staffing needs. According to Diana Rupert, when Westmoreland County Community College (WCCC) began offering LPN training at a lower cost than Indiana County Technology Center (ICTC), the latter college stopped producing LPNs. But in 2005, WCCC began focusing on RN training, which left a void for educating in-demand LPNs in the area. With persistence, funding from the Indiana County consortium, and support from Westmoreland, ICTC restarted its LPN program. Health care employers are also providing scholarships for employees to attend Indiana County Tech Center's LPN program. Further, to help facilitate career progression, ICTC's vocational training program for LPNs includes college courses as part of the curriculum. For example, students wanting to pursue an $\mathrm{RN}$ degree can complete some of their required courses through ICTC before entering a community college.

\section{TIME COMMITMENT}

Time constraints are an issue for many involved with the Tri-County Partnership. With one exception-Mary Salony, director of planning and grant coordination at the Tri-County WIB, who is paid for the administrative support she provides to the Tri-County Partnership — the business owners, directors of educational programs, and admission directors we interviewed are volunteers. The time they spend attending consortium meetings, reviewing applications for scholarships, assessing training proposals, and planning events is in addition to their full-time day jobs and is all voluntary. Yet everyone we spoke with believes the partnership is well worth their time and effort. They mentioned the ability to engage with others who are struggling with similar employment challenges, discussing ways to adapt to an ever-changing and more complex health care delivery system, and the opportunity to share training resources as benefits to the partnership.

Networking and knowledge sharing among members in particular were cited as key benefits to the partnership. "Health care is getting increasingly complex," observed Susie Tack Beardsley, chair of the Butler County Health Care Consortium and an owner of several nursing homes. "Just when you think it can't get more complicated, it does, so you can try to deal with issues in a vacuum or work with others in a similar predicament."
Notably, those in the partnership choose to work together despite in some cases being competitors. Noted Kelly Howells, co-chair of the Indiana Consortium and owner of a home health agency, "We are competitors in the room, but having a forum where we can vet ideas and learn how others addressed issues one of us is now facing is so important.”

\section{FUNDING}

Another constraint interviewees mentioned is funding. Noted one, "Funding was not the main priority in the beginning - it was learning about employers' workforce needs. We were able to secure funding [only] after we began working together and could identify these needs." Given the ongoing demand for skilled health care workers, the partnership is continuing to identify ways to raise additional revenue for training. Two of the three county consortia have nonprofit status, which allows for taxdeductible donations and facilitates grant funding where nonprofit status is a prerequisite. This status, relatively new for the consortia, indicates the partnership is thinking about sustainability, especially with decreases in funding from the state.

\section{COLLABORATION}

The commitment of the Tri-County steering committee to the partnership is evident in the length of service of many of its members. A few have been engaged since 2002; others have been involved for almost ten years. This tenure and continuity in leadership has contributed greatly to the trust, collaboration, and problem solving among the consortium members.

It should be noted that not every employer in the three consortia benefits directly from a given training. Members of the steering committee decide what training is most needed for the employers in the region as a whole; these selections may benefit an individual employer in one year, but not in other years. This impartial approach speaks to the partnership's focus on meeting the workforce needs of the industry, versus those of individual employers.

As Susie Tack Beardsley, the longstanding chair of the Butler County Consortium, noted, "These meetings could become gripe sessions among members, but we keep our focus on getting to solutions." Beardsley mentioned the importance of having members who are decision makers. "Membership is not about making contacts or marketing services," she noted. "It is about tackling similar regulatory issues and identifying training and staffing needs." 


\section{Conclusion}

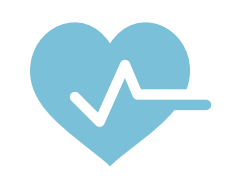

A collective approach allows the partnership to identify common training needs, allocate limited resources, and provide expertise for the benefit of the health care industry in western Pennsylvania.
While an acute shortage of nurses is no longer the pressing issue it was when the partnership formed, the need for skilled health care workers remains strong in the Tri-County region. Kimberly Doms, co-chair of the Armstrong Consortium and the director of the Licensed Practical Nursing program at Lenape Tech, insisted that demand remains high: "Employers come in to actively recruit from my graduating classes. Nearly half of my students were hired before even graduating [this past] September."

The critical worker shortage is one that no member of the partnership wants repeated. "By talking with others in the field, we can stay on top of employment needs of the industry now," stated Doms. With more than ten years behind it, the partnership remains committed to meeting the health care needs of the region through training, education, and increasing interest in the field. Doing this collectively rather than separately has allowed the partnership to identify common training needs, use the limited training resources more efficiently, and provide in-kind staff expertise to each other through mentoring, job shadowing, and teaching.

But time remains a challenge. "We can't move at lightning speed because we all have full-time jobs," observed Doms, who then added, "We find the time because what we do matters." Enhancing employees' skills through training, securing the funding to do so, and collectively identifying and solving issues impacting health care services in the region are all accomplishments of the partnership. According to the employers we spoke with, having better-trained health care staff positively impacts productivity and increases the quality of patient care. While admittedly difficult to measure, Diana Rupert said, "I truly believe the work of the health care consortia has positively impacted anyone receiving health care services in this region."

Author Lisa Nelson is the Community Development Advisor at the Federal Reserve Bank of Cleveland. 
Authors: Kyle Fee, Matthew Klesta, and Lisa Nelson, Federal Reserve Bank of Cleveland

Published by the Federal Reserve Bank of Cleveland's Community Development Department.

The views expressed in this publication are those of the authors; these views do not necessarily reflect those of the Federal Reserve Bank of Cleveland, the Federal Reserve Board of Governors, or the Federal Reserve System. Reprinting allowed with permission; contact Managing Editor Anne O'Shaughnessy at Anne.oshaughnessy@clev.frb.org.

Members of the Cleveland Fed Community Development Department include

\section{CLEVELAND}

Paul Kaboth

Vice President \&

Community Development Officer

216.579.2951

Paul.kaboth@clev.frb.org

Mary Helen Petrus

Assistant Vice President

216.579.2443

Mary.h.petrus@clev.frb.org

Brett Barkley

Research Analyst

216.206.3658

Brett.barkley@clev.frb.org

Kyle Fee

Regional Community

Development Advisor

216.579.2029

Kyle.d.fee@clev.frb.org

Matthew Klesta

Policy Analyst

216.579.3166

Matthew.klesta@clev.frb.org

Hal Martin

Policy Economist

216.774.2526

Hal.martin@clev.frb.org

Lisa Nelson

Community Development Advisor 216.579.2903

Lisa.a.nelson@clev.frb.org

Anne O'Shaughnessy

Communications Advisor

216.579.2233

Anne.oshaughnessy@clev.frb.org

Ann Marie Wiersch

Senior Policy Analyst

216.579.2423

Annmarie.wiersch@clev.frb.org
PITTSBURGH

Joseph Ott

Regional Community

Development Advisor

412.261 .7947

Joseph.c.ott@clev.frb.org

CINCINNATI

Bonnie Blankenship

Regional Community

Development Advisor

513.455.4281

Bonnie.blankenship@clev.frb.org
CONNECT WITH THE CLEVELAND FED 
www.clevelandfed.org/communitydevelopment 